International Journal of Pure and Applied Mathematics

Volume 85 No. 2 2013, 241-253

ISSN: 1311-8080 (printed version); ISSN: 1314-3395 (on-line version)

url: http://www.ijpam.eu

doi: http://dx.doi.org/10.12732/ijpam.v85i2.5

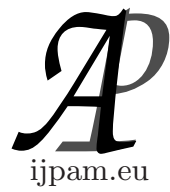

\title{
NOVEL SIGN OF SUPER EDGE-MAGIC GRAPH
}

\author{
A. Vijayabarathi ${ }^{1}{ }^{\S}$, G.S.G.N. Anjaneyulu ${ }^{2}$ \\ 1,2 Applied Algebra Division \\ School of Advanced Sciences \\ VIT University \\ Vellore-14, Tamilnadu, INDIA
}

\begin{abstract}
In this paper, we introduce a new concept of super edge-magic sequence (SEMS) of a super edge-magic graph (SEMG) with p vertices and $q$ edges. The super edge-magic sequence of natural numbers is denoted by $<x_{i}>, 1 \leq i \leq q$. This sequence need not to be monotonic. In this track, we also drive some families of super edge-magic graphs from fabrication of new super edge-magic sequences by considering additional parameter. We complete this paper by discussing the special case like monotonic sequences related to the super edge-magic sequence.
\end{abstract}

AMS Subject Classification: 05C78,05C99

Key Words: edge-magic graph, super edge-magic graph, super edge-magic sequence

\section{Introduction}

\subsection{Background of Edge-Magic and Super Edge-Magic Graphs}

Kotzig and Rosa introduced the concepts of magic valuation [11]. Ringel and Llado [15] called this type of valuation as edge-magic labeling. Enomoto et. al.[4] restricted the notion of edge -magic labeling of a graph to obtain the definition of super edge-magic labeling. A $(\mathrm{p}, \mathrm{q})$ graph $\mathrm{G}$ is called edge-magic if there exists a bijective function $f: V(G) \cup E(G) \longrightarrow\{1,2,3, \ldots, p+q\}$ such

Received: November 9, 2012

(C) 2013 Academic Publications, Ltd. url: www.acadpubl.eu

${ }^{\S}$ Correspondence author 
that $f(u)+f(v)+f(u v)=k$ is a magic constant for any edge uv $\in \mathrm{E}(\mathrm{G})$. Moreover, $\mathrm{G}$ is said to be super edge-magicif $f(V(G)) \longrightarrow\{1,2,3, \ldots, p\}$. The following Lemma from [13] provides a necessary and sufficient condition for a graph to be super edge-magic.

Lemma 1.1. A graph $G$ with $p$ vertices and $q$ edges is super edge-magic if and only if there exists a bijective function $f: V(G) \longrightarrow\{1,2,3, \ldots, p\}$ such that the set $S=\{f(x)+f(y) / x y \in E(G)\}$ consists of q consecutive integers. In such a case, $f$ extends to a super edge-magic total labeling of $G$ with the magic constant $c=p+q+\min (S)$.

Lemma 1.2. If a graph $G$ with $p$ vertices and $q$ edges is super edge-magic then $q \leq 2 p-3$.

Lemma 1.3. Let $G$ be a triangle free super edge-magic graph with $p(\geq 4)$ vertices and $q$ edges. Then, $q \leq 2 p-5$.

\subsection{Road Map of the Paper}

The rest of the paper is organized as follows: In Section 2, we introduce the concept of super edge-magic sequence and construction of SEMG from SEMS. Also we give the limitations and upshots of super edge-magic sequence. Section 3 , includes fabrication of new super edge-magic sequences and we drive some families of super edge-magic graphs. The last section covers a special case of sequence like monotonic sequence with their behavior in SEMS.

\section{Proposed Work}

\subsection{Definition and Construction}

Now we define the concept of super edge-magic sequence and transmit it to the graph. We describe super edge-magic sequence analogously for graceful sequence [1], [2] and [3].

Definition 2.1. (Super Edge-Magic Sequence) Let G be a super edge magic graph with $\mathrm{p}$ vertices and q edges. Here we introduce a new term i.e. a constant of super edge-magic sequence and is denoted by $\alpha^{*}$. A Sequence $\left\langle x_{i}\right\rangle$ is said to be super edge- magic sequence if

$$
\max _{1 \leq i \leq q}\left\{2 x_{i}+i\right\}<\alpha^{*}+q \leq p+\min _{1 \leq i \leq q}\left\{x_{i}+i\right\} \ldots \ldots .(2.1 . a)
$$


Where $x_{i}$ is always the lower end vertex of the edge label $\mathrm{p}+\mathrm{i}, 1 \leq i \leq q$ i.e., $x_{i}$ $=\min \{f(x), f(y) / x y \in E(G)\}$ and $\alpha^{*}=\min (\mathrm{S})$, Where $S=\{f(x)+f(y) / x y \in$ $E(G)\}$. We illustrate a super edge-magic sequence of Figure 1. SEMS of a

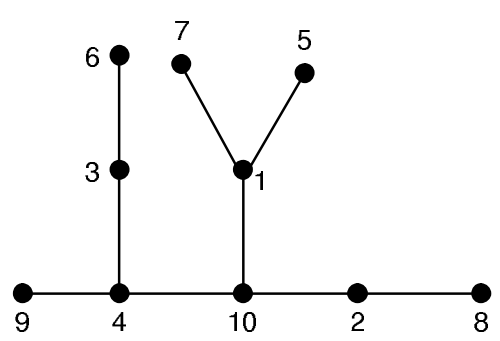

Figure 1

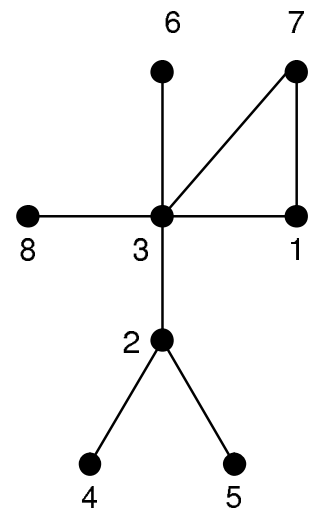

Figure 2

SEM Graph : Suppose $(4,4,2,1,2,3,1,3,1)$ is a given sequence. For $1 \leq i \leq q$, $\max \left\{2 x_{i}+i\right\}=14, \min \left\{x_{i}+i\right\}=5, \alpha^{*}=6, p=10, q=9$. Then above data satisfies the condition (2.1.a).

Note 2.1. In this entire paper sequence means super edge-magic sequence.

\subsection{Edifice of a Super Edge-Magic Graph from the Sequence}

Let $\left(x_{1}, x_{2}, x_{3}, \ldots, x_{q}\right)$ be the sequence having ' $\mathrm{q}$ ' terms. Compute $\alpha^{*}$ and $\mathrm{p}$ using the condition (2.1.a) as follows:

$$
\text { Letm }=\max _{1 \leq i \leq q}\left\{2 x_{i}+i\right\} \text { and } n=\min _{1 \leq i \leq q}\left\{x_{i}+i\right\}
$$

Then by (2.1.a), $m<\alpha^{*}+q \leq p+n$. In this construction, $\alpha^{*}$ is independent for $\alpha^{*} \geq m-q+1$. Based on particular $\alpha^{*}$, and by (2.1.a) choose $p \geq \alpha^{*}+q-n$. For every $\alpha^{*}$, there exist many p values such that all they must give super edgemagic graphs. Here we note that each $\mathrm{p}$ in this domain, the super edge-magic graph is unique. Identify the edges of super edge-magic graph corresponding a particular $\alpha^{*}$ and ' $p$ ' by the following way: 
The super edge-magic graph can be drawn by identifying all the edges like above.

Concrete Example. Suppose the given sequence is $(3,3,3,1,2,2,2,1)$, $\mathrm{q}=8$, $\mathrm{m}=11$ and $\mathrm{n}=4$. On simplification of (2.1.a), we obtain $3<\alpha^{*} \leq p-$ 4. The possibilities of $\alpha^{*}$ and $\mathrm{p}$ is respectively: $\alpha^{*}=\{4,5,6, \ldots$,$\} and \mathrm{p}$ $=\{8,9,10, \ldots$,$\} . In this domain of \alpha^{*}$ and $\mathrm{p}$, given sequence is super edge-magic sequence. For $\alpha^{*}=4, \mathrm{p}=\{8,9,10, \ldots\}$.If $\alpha^{*}=4$, and we select appropriate $\mathrm{p}=$ 8. We identify the edges by the following way:

Then the super edge-magic graph is shown in Figure 2

\subsection{Limitations and Upshots of Super Edge-Magic Sequence}

Lemma 2.3.1. Let $\left(x_{1}, x_{2}, \ldots, x_{q}\right)$ be any super edge-magic sequence. $x_{i}$ denotes lower end vertex of the edge label $p+i, 1 \leq i \leq q$ Then lower end vertex is always strictly less than the upper end vertex,i.e., $x_{i}<\alpha^{*}+q-i-x_{i}$ and upper end vertex is less than or equal to $p$.

Proof. Let $\left(x_{1}, x_{2}, \ldots, x_{q}\right)$ be any super edge-magic sequence. Then by definition (2.1), this sequence satisfies the condition (2.1.a).

From LHS of (2.1.a): $x_{i}<\alpha *+q-i-x_{i}$ for all i, $1 \leq i \leq q$

From RHS of (2.1.a): $\alpha *+q-i-x_{i} \leq p$ for all $\mathrm{i}, 1 \leq i \leq q$ Also from (2.3.a) and (2.3.b), $x_{i}<\alpha *+q-i-x_{i} \leq p$ This completes the proof.

Proposition 2.3.1. Let $\left\langle x_{i}\right\rangle, 1 \leq i \leq q$ be any super edge-magic sequence. The lower end vertex is at most $p$-1. i.e., $x_{i} \leq p-1$.

Theorem 2.3.1. A graph is a super edge-magic graph if and only if $G$ has super edge- magic sequence.

Proof. Necessary Part. Let $\left(x_{1}, x_{2}, \ldots, x_{q}\right)$ be super edge-magic sequence. Then by definition (2.1), it has one super edge-magic graph.

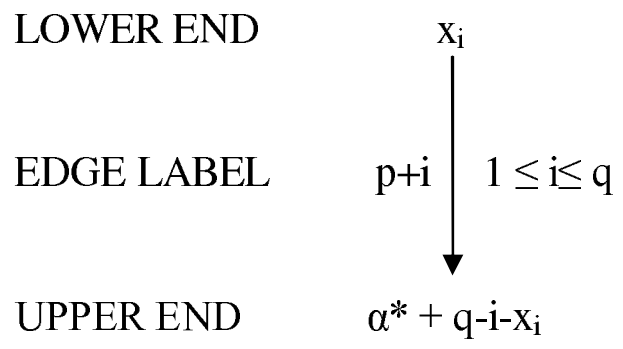


Sufficient Part. Let us assume that $\mathrm{G}$ is super edge-magic. Here $\alpha *=$ $\min \{f(u)+f(v) / u v \in E(G)\}$ and $S=\{\alpha *, \alpha *+1, \alpha *+2, \ldots, \alpha *+q-1\}$ has $" q "$ consecutive integers. i.e., $S=\{\alpha *+q-i / 1 \leq i \leq q\}$ For each edge e=uv $\in E(G), x_{i}=\min \{f(u), f(v) / f(u)+f(v)=\alpha *+q-i / 1 \leq i \leq q\}$ The other end is $\alpha *+q-i-x_{i}, \forall i, 1 \leq i \leq q$. By the second part of the lemma (2.3.1),

$$
\alpha *+q \leq p+\min _{1 \leq i \leq q}\left\{x_{i}+i\right\} \ldots .(2.3 . c)
$$

And the first part of the lemma (2.3.1),

$$
\max _{1 \leq i \leq q}\left\{2 x_{i}+i\right\}<\alpha *+q \ldots .(2.3 . d)
$$

From (2.3.c) and (2.3.d), $\left(x_{1}, x_{2}, \ldots, x_{q}\right)$ is super edge-magic sequence. This completes the proof.

\section{Fabrication of New Super Edge-magic Sequences}

In this section, we fabricate new SEMS of SEMG by means of extension. We will do this construction as explained analogously in [1], [2].

Theorem 3.1. If $\left(x_{1}, x_{2}, \ldots, x_{q}\right)$ represents a super edge-magic sequence of a graph $G$ on "q" edges with

$$
\begin{array}{r}
\alpha *(<x i>)=\max _{1 \leq i \leq q}\left\{2 x_{i}+i\right\}+1-q \ldots \ldots .(3 . a) \\
p\left(<x_{i}>\right)=\max _{1 \leq i \leq q}\left\{2 x_{i}+i\right\}-\min _{1 \leq i \leq q}\left\{x_{i}+i\right\}+1 \ldots \ldots .(3.6
\end{array}
$$

Then the sequence $\left(x^{*}+1-x_{1}, x^{*}+1-x_{2}, \ldots, x^{*}+1-x_{q-1}, x^{*}+1-\right.$ $\left.x_{q}, x_{1}, x_{2}, \ldots, x_{q}\right)$ represents super edge-magic sequence on $2 q$ edges with same $\alpha *$, for $x^{*}=\max \left\{x_{i} / 1 \leq i \leq q\right\}$.

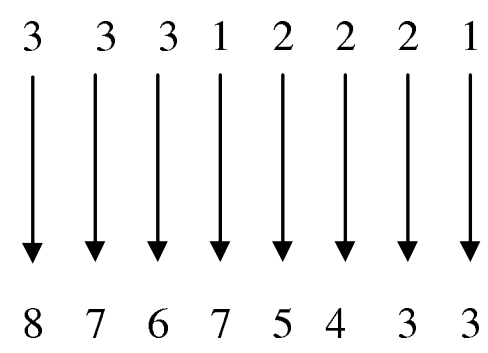


Proof. Let $y_{i}=x^{*}+1-x_{i}, \quad 1 \leq i \leq q y_{q}+i=x_{i}, \quad 1 \leq i \leq q$ Then the sequence becomes: $\left(y_{1}, y_{2}, y_{3} \ldots y_{q}, y_{q+1}, \ldots, y_{2 q}\right)$

$$
\max _{1 \leq i \leq q}\left\{2 y_{i}+i\right\} \leq 2 x^{*}+q \ldots \ldots(3 . c)
$$

Suppose $x^{*}$ is occurring in the position of the least label ' $r$ ' in the sequence $<x_{i}>$

$$
\begin{gathered}
2 x^{*}+q<2 x^{*}+q+r \leq \max _{1 \leq i \leq q}\left\{2 y_{q+i}+q+i\right\} \\
=\max _{1 \leq i \leq q}\left\{2 x_{i}+i\right\}+q \\
=\alpha *\left(<x_{i}>\right)+2 q-1 b y(3 . a)
\end{gathered}
$$

$2 x *+q<\alpha *\left(<x_{i}>\right)+2 q-1 \ldots . .(3 . d)$

$$
\begin{array}{r}
\max _{q+1 \leq i \leq 2 q}\left\{2 y_{i}+i\right\}=\max _{1 \leq i \leq q}\left\{2 x_{i}+i\right\}+q \\
\max _{q+1 \leq i \leq 2 q}\left\{2 y_{i}+i\right\}=\alpha *\left(<x_{i}>\right)+2 q-1 \ldots \ldots .
\end{array}
$$

using (3.c) and (3.e)

$$
\begin{gathered}
\max _{1 \leq i \leq 2 q}\left\{2 y_{i}+i\right\}=\alpha *\left(<x_{i}>\right)+2 q-1 \ldots \ldots(3 . f) \\
\text { Byapplying }(3 . a), \alpha *\left(<y_{i}>\right)=\max _{1 \leq i \leq 2 q}\left\{2 y_{i}+i\right\}+1-2 q \\
=\alpha *\left(<x_{i}>\right)(\text { by } 3 . f)
\end{gathered}
$$

$\alpha *\left(<y_{i}>\right)=\alpha *\left(<x_{i}>\right)$.

This completes the proof.

Corollary 3.1. If $\left(x^{*}+1-x_{1}, x^{*}+1-x_{2}, \ldots, x^{*}+1-x_{q-1}, x^{*}+1-\right.$ $\left.x_{q}, x_{1}, x_{2}, \ldots, x_{q}\right)$ represents super edge-magic sequence on $2 q$ edges satisfying the conditions in theorem 3.1 then the number of vertices is given by

$$
\alpha *\left(<x_{i}>\right)+2 q-\min _{1 \leq i \leq 2 q}\left\{y_{i}+i\right\}
$$

Proof. Using the Theorem 3.1:

$$
\begin{gathered}
\min _{1 \leq i \leq 2 q}\left\{y_{i}+i\right\}=\min _{1 \leq i \leq q}\left\{y_{i}+i\right\} \\
=\min _{1 \leq i \leq q}\left\{\left(x^{*}+1-x_{i}\right)+i\right\}
\end{gathered}
$$


(by 3.b) and we have

$$
\begin{gathered}
p\left(<y_{i}>\right)=\alpha *\left(<x_{i}>\right)+2 q-\min _{1 \leq i \leq q}\left\{\left(x^{*}-x_{i}\right)+i+1\right\} \\
p\left(<y_{i}>\right)=\alpha *\left(<x_{i}>\right)+2 q-\min _{1 \leq i \leq 2 q}\left\{y_{i}+i\right\}
\end{gathered}
$$

This completes the proof.

$\triangleright$ Let us illustrate the theorem and corollary of 3.1, by the following:

Suppose $\left\langle x_{i}\right\rangle=(3,2,2,1,1)$, by the theorem 3.1, $\alpha *=3, p\left(G_{1}\right)=$ $\left.4, x^{*}=3,<y_{i}\right\rangle=(1,2,2,3,3,3,2,2,1,1)$, and by corollary $3.1, p\left(G_{2}\right)=11$. Then the graph as shown in Figure 3:

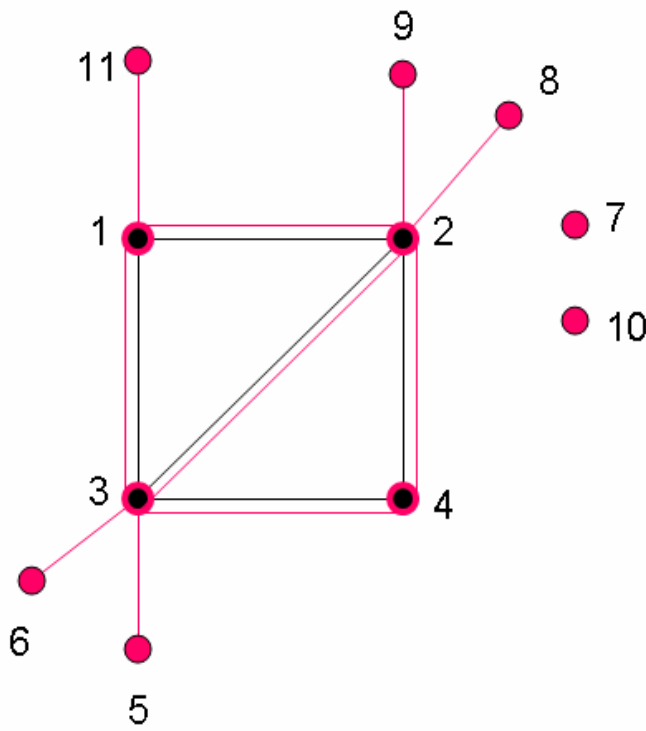

Figure 3

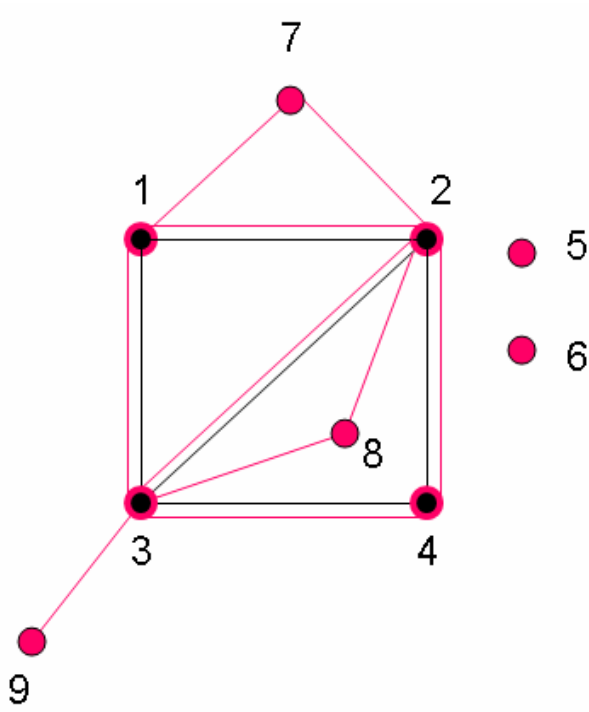

Figure 4

Theorem 3.2. If $\left(x_{1}, x_{2}, \ldots, x_{q}\right)$ represents a super edge-magic sequence of a graph $G$ on ' $q$ ' edges with

$$
\begin{array}{r}
\alpha *\left(<x_{i}>\right)=\max _{1 \leq i \leq q}\left\{2 x_{i}+i\right\}+1-q \ldots \ldots .(3 . g) \\
p\left(<x_{i}>\right)=\max _{1 \leq i \leq q}\left\{2 x_{i}+i\right\}-\min _{1 \leq i \leq q}\left\{x_{i}+i\right\}+1 \ldots \ldots(3 .
\end{array}
$$


Then $\left(x_{*}+1-x_{q}, x_{*}+1-x_{q-1}, \ldots, x^{*}+1-x_{2}, x^{*}+1-x_{1}, x_{1}, x_{2}, \ldots, x_{q}\right)$ represents super edge-magic sequence on $2 q$ edges with same $\alpha *$, for $x^{*}=$ $\max \left\{x_{i} / 1 \leq i \leq q\right\}$.

Proof. Let $y_{i}=x^{*}+1-x_{q}-i+1,1 \leq i \leq q y_{q+i}=x_{i}, 1 \leq i \leq q$ The given sequence becomes: $\left(y_{1}, y_{2}, \ldots, y_{q}, y_{q+1}, \ldots, y_{2 q}\right)$

$$
\begin{gathered}
\max _{1 \leq i \leq q}\left\{2 y_{i}+i\right\}=\max _{1 \leq i \leq q}\left\{2\left(x^{*}+1-x_{q-i+1}+i\right\}\right. \\
=2 x^{*}+2-\min _{1 \leq i \leq q}\left\{2 x_{q-i+1}+i\right\} \\
\max _{1 \leq i \leq q}\left\{2 y_{i}+i\right\}<2 x^{*}+q \ldots \ldots(3 . i)
\end{gathered}
$$

Using theorem 3.1, $2 x *+q<\alpha *\left(<x_{i}>\right)+2 \mathrm{q}-1$ and By (3.e)

$$
\max _{q+1 \leq i \leq 2 q}\left\{2 y_{i}+i\right\} \leq \alpha *\left(<x_{i}>\right)+2 q-1 \ldots \ldots
$$

By (3.i) and (3.j),

$$
\begin{aligned}
& \max _{1 \leq i \leq 2 q}\left\{2 y_{i}+i\right\}=\alpha *\left(<x_{i}>\right)+2 q-1 \\
& \alpha *\left(<y_{i}>\right)=\max _{1 \leq i \leq 2 q}\left\{2 y_{i}+i\right\}+1-2 q
\end{aligned}
$$

By applying (3.g) $\alpha *\left(<y_{i}>\right)=\alpha *(<x i>)$

This completes the proof.

Corollary 3.2. If $\left(x^{*}+1-x_{q}, x^{*}+1-x_{q-1}, \ldots, x^{*}+1-x_{2}, x^{*}+1-\right.$ $\left.x_{1}, x_{1}, x_{2}, \ldots, x_{q}\right)$ represents super edge-magic sequence on $2 q$ edges satisfying the conditions in theorem 3.2 then the number of vertices is given by

$$
\alpha *\left(<x_{i}>\right)+2 q-\min _{1 \leq i \leq 2 q}\left\{y_{i}+i\right\}
$$

Proof. The sequence $\left\langle y_{i}>\right.$ and other details are followed by theorem 3.2.

$$
\begin{gathered}
\min _{1 \leq i \leq 2 q}\left\{y_{i}+i\right\}=\min _{1 \leq i \leq q}\left\{\left(x^{*}+1-x_{q-i+1}\right)\right\} \\
=(x *+1)-\max _{1 \leq i \leq q}\left\{\left(x_{q-i+1}\right)\right\} \\
p(<y i>)=\max _{1 \leq i \leq 2 q}\left\{2 y_{i}+i\right\}-\min _{1 \leq i \leq 2 q}\left\{y_{i}+i\right\}+1
\end{gathered}
$$




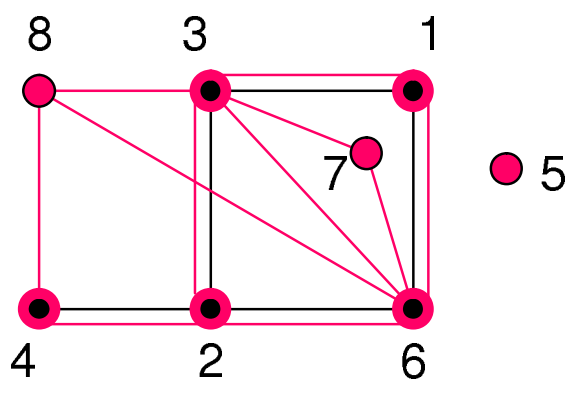

Figure 5

By using (3.h)

$$
p(<y i>)=\alpha *(<x i>)+2 q-\min _{1 \leq i \leq 2 q}\left\{y_{i}+i\right\}
$$

This completes the proof.

$\triangleright$ Concrete Example for the theorem and corollary of 3.2: Suppose $\left.<x_{i}\right\rangle=(3,2,2,1,1)$, by using theorem $3.2, \alpha *=3, p\left(G_{1}\right)=4, x^{*}=3,<$ $y_{i}>=(3,3,2,2,1,3,2,2,1,1)$, and by corollary $3.2, p\left(G_{2}\right)=9$. Then the graph as shown in Figure 4.

Theorem 3.3. If $\left(x_{1}, x_{2}, \ldots, x_{q}\right)$ represents a super edge-magic sequence with

$$
\alpha *\left(<x_{i}>\right)=\max _{1 \leq i \leq q}\left\{2 x_{i}+i\right\}+1-q
$$

and

$$
p\left(<x_{i}>\right)=\max _{1 \leq i \leq q}\left\{2 x_{i}+i\right\}-\min _{1 \leq i \leq q}\left\{x_{i}+i\right\}+1
$$

Then $\left(\alpha *+q-1-x_{1}, \alpha *+q-2-x_{2}, \ldots, \alpha *-x_{q}, \lambda, x_{1}, x_{2}, \ldots, x_{q}\right)$ represents a super edge-magic sequence on $2 q+1$ edges with same $\alpha *$, choose $\lambda$ such that $1 \leq \lambda<q$.

Proof. This is an immediate consequence of definition and by applying theorem 3.1.

Remark 3.1. Based on the parameter $\left\langle x_{i}\right\rangle, \mathrm{q}, \alpha *$, At least one $\lambda$ such that $1 \leq \lambda<q$ would give SEMG.

$\triangleright$ Let us illustrate the theorem and corollary of 3.3 as follows: $\left\langle x_{i}\right\rangle=$ $(2,1,2,2,1), \alpha *=4, p\left(G_{1}\right)=6,<y_{i}>=(6,6,4,3,3,3,2,1,2,2,1), \lambda=3, p\left(G_{2}\right)=8$. Figure 5 shows the graph. 
Remark 3.2. Theorems from 3.1 to 3.3 have the same property that the sequence $\left\langle x_{i}\right\rangle$ and $\left\langle y_{i}>\right.$ have same $\alpha *$. Each sequence gives one super edgemagic graph say $G_{1}, G_{2}$ respectively then the graph $G_{2}$ contains $G_{1}$ always. $G_{1}$ indicated by block color and $G_{2}$ indicated by pink color.

Theorem 3.4. If $\left(x_{1}, x_{2}, \ldots, x_{q}\right)$ represents a super edge-magic sequence of a graph $G$ on "q" edges with

$$
\begin{gathered}
\alpha *\left(<x_{i}>\right)=\max _{1 \leq i \leq q}\left\{2 x_{i}+i\right\}+1-q \\
p\left(<x_{i}>\right)=\max _{1 \leq i \leq q}\left\{2 x_{i}+i\right\}-\min _{1 \leq i \leq q}\left\{x_{i}+i\right\}+1
\end{gathered}
$$

Then $\left(2 x_{1}+1,2 x_{1}, 2 x_{2}+1,2 x_{2}, \ldots, 2 x_{q}+1,2 x_{q}\right)$ represents super edge-magic sequence of a graph $H$ such that $\alpha *(H)=2 \alpha *(G)$ and $p(H)=2 p(G)$.

Proof. This is an immediate consequence on modification of $\left\langle x_{i}\right\rangle$ by definition.

Remark 3.3. $\alpha *$ of $\mathrm{H}$ is twice number of $\alpha *$ of $\mathrm{G}$, so that the structure of the graph $\mathrm{G}$ is embedded in $\mathrm{H}$ and also the labeling of $\mathrm{G}$ is exactly doubled.

$\triangleright$ Let us illustrate the theorem 3.4.by the following: In the succeeding figures the color green indicates the graph $\mathrm{G}$ and blue indicates $\mathrm{H}$.

- If $\mathrm{G}$ has one connected component then the corresponding $\mathrm{H}$ as follows: $\left\langle x_{i}\right\rangle=(4,4,2,1,2,3,1,3,1), \alpha *(\mathrm{G})=6, \mathrm{p}(\mathrm{G})=10, \mathrm{q}(\mathrm{G})=9$. The sequence for $\mathrm{H}$ $=(9,8,9,8,5,4,3,2,5,4,7,6,3,2,7,6,3,2), \mathrm{p}(\mathrm{H})=20, \mathrm{q}(\mathrm{H})=18, \alpha *(\mathrm{H})=12$. Then the graph as shown in Figure 6

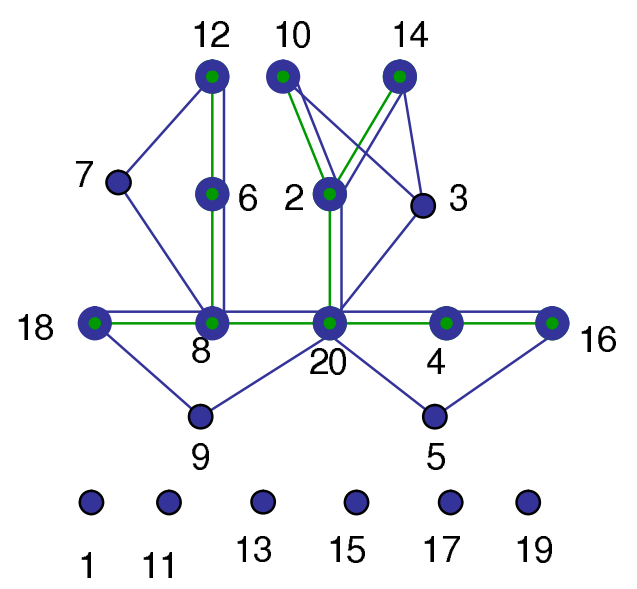

Figure 6

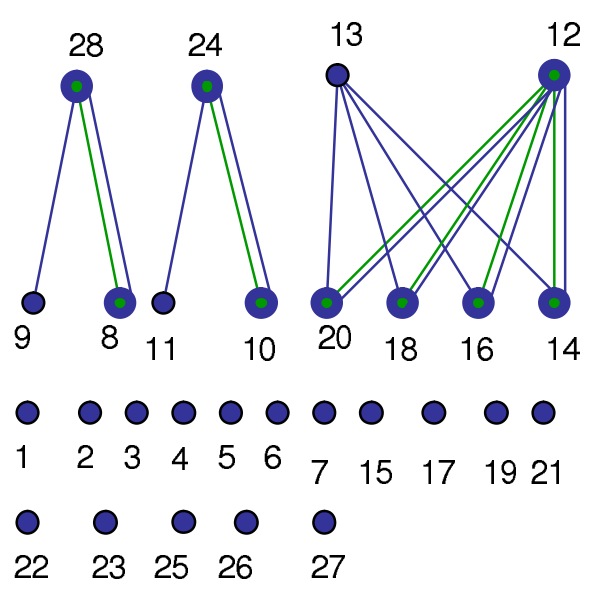

Figure 7 
- If $\mathrm{G}$ has more than one connected components the corresponding $\mathrm{H}$ as follows: $\left\langle x_{i}\right\rangle=(4,5,6,6,6,6) \alpha *(\mathrm{G})=13, \mathrm{p}(\mathrm{G})=14, \mathrm{q}(\mathrm{G})=6$. The sequence for $\mathrm{H}=(9,8,11,10,13,12,13,12,13,12,13,12), \alpha *(\mathrm{H})=26, \mathrm{p}(\mathrm{H})=28, \mathrm{q}(\mathrm{H})=12$. Then the graph as shown in Figure 7

Proposition 3.1. If any super edge-magic sequence does not contain the element ' 1 ', then (m-1) number of deficiency can be reduced by subtracting $(m-1)$ in each element of that sequence, where $m$ is minimum element of the given super edge-magic sequence.

Proof. This is an immediate consequence of theorem 3.4.

\section{Monotonic Sequences and their Behavior in Super Edge-Magic Graph}

Proposition 4.1. If the sequence $\left\langle x_{i}\right\rangle, 1 \leq i \leq q$ defines a super edgemagic graph with $x_{1} \geq x_{2} \geq x_{3} \geq \cdots \geq x_{q}(=1)$ then the feasible range of $\alpha *$ is $x_{q}+2 \leq \alpha * \leq x_{1}+2$.

The range of $\alpha *$ is $\left(x_{q}+2, x_{1}+2\right)$ but all $\alpha *$ need not give super edge-magic graph. To find $\alpha *$ which will give super edge-magic graph from the following.

Proposition 4.2. Let $\left\langle x_{i}\right\rangle, 1 \leq i \leq q$ be super edge-magic sequence such that $x_{1} \geq x_{2} \geq x_{3} \geq \cdots \geq x_{q}$ with $x_{q}=1$,

$$
\alpha=\max _{1 \leq i \leq q}\left\{2 x_{i}+i\right\} \text { and } \beta=\min _{1 \leq i \leq q}\left\{x_{i}+i\right\}
$$

. Then the number of super edge-magic graph is $(q+1)-(\alpha-\beta)$ which is denoted by ' $r$ '. Moreover, the value of $\alpha *$ is $\alpha-q+j, 1 \leq j \leq r$ and the corresponding value of $p$ is at least $\alpha *-\beta+q$.

Definition 4.1. Let $\left\langle x_{i}\right\rangle, 1 \leq i \leq q$ be super edge-magic sequence such that $x_{1} \leq x_{2} \leq x_{3} \leq \ldots, \leq x_{q}$ then number of digits appeared in the sequence $\left.<x_{i}\right\rangle, 1 \leq i \leq q$ is said to be "orderofthesequence" and denoted by ' $n$ '.

Proposition 4.3. Let $\left\langle x_{i}\right\rangle, 1 \leq i \leq q$ be super edge-magic sequence such that $x_{1} \leq x_{2} \leq x_{3} \leq \ldots, \leq x_{q}$ with $x_{1}=1$. Then $\alpha *=2 x_{q}+1, p=2 x_{q}+q-1$ must be super edge-magic graph with deficiency[13] is n-1.

\section{Conclusion}

The relevance of this paper is two fold. First, we introduced definition of SEMS and construction method for SEMG from SEMS. In a consequent step, 
the limitations and upshots of SEMS were also discussed. Second, Fabrication of New SEMS and behavior of monotonic sequences of super edge-magic graph were discussed.

\section{References}

[1] K. Balasubramaniyan, N. Chandramowliswaran, N. Ramachandran, PawanKumar, Generation of graceful trees through graceful codes, In: Internet. Conf. on Number Theory and Combinaories, SASTRA University, December (2006).

[2] K. Balasubramaniyan, S. Arun, N. Chandramowliswaran, Algorithm for a given code of a graceful tree, In: Internet. Conf. On Number Theory and Combinaories SASTRA University, December (2006).

[3] K. Balasubramaniyan, N. Chandramowliswaran, Tree generation theorems, In: Kyoto. Conf. on Computational Geometry and Graph Theory-in honor of Jin Akiyama Vasek Chvatal on their 60th birthday, June 11-15 (2007) Kyoto, Japan.

[4] H. Enomoto, A. Llado, T. Nakamigawa, G. Ringel, Super edge magicgraphs, SUT J. Math., 34 (1998), 105-109.

[5] R.M. Figueroa-Centeno, R. Ichishima, F.A. Muntaner-Batle, On super edge-magic deficiency of graphs, In. Electron Notes Discrete Math., Volume 11, Elsevier, Amsterdam (2002).

[6] R.M. Figueroa-Centeno, R. Ichishima, F.A. Muntaner-Batle, The place of super edge-magic labeling among other classes of labeling, Discrete Mathematics, 23, No. 1 (2001), 153-168.

[7] R.M. Figueroa-Centeno, R. Ichishima, F.A. Muntaner-Batle, On edgemagic labeling of certain disjoint unions of graphs, Australasian Journal of Combinatorics, 32 (2005), 225-242.

[8] R.M. Figueroa-Centeno, R. Ichishima, F.A. Muntaner-Batle, On super edge magic-graphs, Ars. Combin., 64 (2002), 81-95.

[9] R.M Figueroa-Centeno, R. Ichishima, F.A. Muntaner-Batle, Magical coronations of graphs, Australasian Journal of Combinatoria, 26 (2002), 199208. 
[10] J.A. Gallin, A dynamic survey of graph labeling, Electron. J. Combin., 17 (2010).

[11] A. Kotzig, A. Rosa, Magic valuations of finite graphs, Canad. Math. Bull., 13 (1970), 451-461.

[12] F.A. Muntaner-Batle, Magic Graphs, Ph.D. Thesis, Universitat Politecnica de Catalunya (2001).

[13] A.A.G. Ngurah, E.T. Baskoro, R. Simanjuntak, S. Uttunggadewa, On super edge-magic strength and deficiency of graphs, In Kyoto CGGT 200\%, LNCS 4535 (2008), 144-154.

[14] A.A.G. Ngurah, E.T. Baskoro, R. Simanjuntak, On super edge-magic deficiency of graphs, Australas. J. Combin., 40 (2008), 3-14.

[15] G. Ringel, A. Llado, Another tree conjecture, Bull. Inst. Combin. Appl., 18 (1996), 83-85.

[16] W.D. Wallis, E.T. Baskoro, M. Miller, Slamin, Edge-magic total labeling, Austral. J. Combin., 22 (2000), 177-190.

[17] Zhibo Chen, On super edge-magic graphs, J. Combin. Math. Combin. Comput., 39 (2001), 107-120. 
